\title{
Ensino de Ciências Biológicas: materiais didáticos para alunos com necessidades educativas especiais
}

\author{
The teaching of Biological Sciences: teaching materials \\ for students with special educational needs
}

\author{
Larissa Ferreira Stella ${ }^{1}$ \\ https://orcid.org/0000-0003-2559-2826 \\ Vânia Galindo Massabni ${ }^{1}$ \\ https://orcid.org/0000-0001-9917-7217
}

\begin{abstract}
Resumo: A legislação e as metas educacionais, atualmente, valorizam a inclusão de alunos com necessidades educacionais especiais, especificamente alunos com deficiência, transtornos globais do desenvolvimento e altas habilidades. Porém, para que a inclusão se efetive no que se refere às Ciências Biológicas, torna-se necessário aprimorar a formação inicial e continuada de professores, bem como a proposição e disponibilidade de recursos ou materiais didáticos apropriados para a aprendizagem da área, enfrentando estas, entre outras questões que dificultam o processo educacional. Se metodologias e recursos diferenciados de ensino facilitam a inclusão destes alunos, precisam ser investigados e propostos. A partir disto, o presente estudo teve como objetivo analisar a diversidade dos materiais didáticos no ensino de Ciências Biológicas (ou Biologia) em revistas acadêmicas de plataformas de pesquisa na internet. Para o levantamento de trabalhos foram consultadas 16 bases de dados, sendo encontrados apenas 18 trabalhos. Constatou-se a necessidade de mais estudos relacionados à criação de recursos didáticos que possam ser utilizados em sala de aula na área de Biologia por alunos com deficiência.
\end{abstract}

Palavras-chave: Educação inclusiva. Material didático. Ensino de biologia. Aluno com necessidades especiais. Pesquisa bibliográfica.

\begin{abstract}
The legislation and the educational goals value the inclusion of students with special educational needs, specifically students with disabilities, global developmental disorders and high skills. However, with regard to Biological Sciences, there is inadequate initial and continuing training of science teachers, and a lack of funding in schools or of suitable teaching resources, among other issues, which hinders the educational process. If differentiated teaching methods and resources are necessary for the inclusion of these students, they need to be investigated and proposed. Considering that, the present study aimed to analyze the diversity of didactic materials for Biological Sciences in journals and research platforms on the Internet. In order to identify the publications, 16 databases were consulted, and 18 items were found. There is a need for more studies related to the creation of didactic resources that can be used in the classroom by students with disabilities, global developmental disorders and high skills.
\end{abstract}

Keywords: Inclusive education. Teaching materials. Biology teaching. Student with special needs. Bibliographic search.

\footnotetext{
${ }^{1}$ Universidade de São Paulo (USP), Escola Superior de Agricultura Luiz de Queiroz (ESALQ), Piracicaba, SP, Brasil. E-mail: massabni@usp.br
} 


\section{Introdução}

Com o processo de evolução da sociedade e esclarecimentos morais, a mudança de comportamento tem influenciado no direito de muitas pessoas, dentre elas, as que possuem alguma deficiência, seja visual, auditiva, motora ou intelectual. Essas pessoas necessitam de oportunidades diferentes para serem incluídas na sociedade, motivo pelo qual é importante que haja maior sensibilidade, de maneira coletiva, de desenvolver capacidades em todos, mas principalmente, naqueles que necessitam maior apoio.

Uma vez que "[...] a educação especial é uma modalidade que perpassa os níveis, etapas e modalidades da educação brasileira e atende a educandos com deficiência, transtornos globais do desenvolvimento e altas habilidades ou superdotação" (BRASIL, 2014b, p. 24), já instituída pela Constituição Federal de 1988 (BRASIL, 1988), esta modalidade se torna o caminho para a inclusão com efetiva aprendizagem, de tais alunos.

Dentre todos os espaços em que a educação se faz presente no dia de uma pessoa, a escola, uma vez destinada ao ensino coletivo que garanta o direito à educação, mostra-se como espaço importante para a inclusão, desde os níveis iniciais. Para que a inclusão se efetive são necessárias reformas estruturais, inovação tecnológica e reestruturação do ensino, de modo que a prática pedagógica exercida pelos profissionais propicie a valorização da diversidade, por meio da participação e aprendizagem do aluno com deficiência, transtornos globais do desenvolvimento e altas habilidades, conforme previsto no Plano de Desenvolvimento da Educação (BRASIL, 2007).

Conforme Mantoan (2001), a temática da inclusão do grupo de alunos com deficiência, transtornos globais do desenvolvimento e altas habilidades, integra-se a uma discussão mais ampla de educação, referente à inclusão de todos no processo educativo, fundamental para outros grupos discriminados, baseado no reconhecimento de sua condição econômica, raça, gênero ou opção sexual, entre outras É uma busca da redução das desigualdades e à valorização da diversidade das pessoas, conforme o Plano Nacional de Educação (PNE) (BRASIL, 2014a).

Segundo dados do Censo 2016 do Inep (figura 1), 57,8\% das escolas brasileiras contavam com alunos com deficiência incluídos em classes comuns. Em 2008 esse percentual era de apenas $31 \%$, o que indica aumento significativo nos últimos anos na matrícula de alunos com deficiência em escolas regulares. Esta constatação demanda melhor formação do professor e preparo das escolas para atender estes alunos, pois, segundo Laguna (2012, p. 15), “[...] no processo de inclusão não é o aluno que deve se adaptar na escola, mas ao contrário, a escola deve adaptar-se de acordo com a necessidade específica do aluno que está inserido no ambiente escolar [...]."

Percebe-se que estes estudantes podem estar na educação básica, frequentando a rede de ensino regular, e podem também estar em escolas exclusivas, que oferecem atendimento educacional especializado. Segundo a Lei de Diretrizes e Bases da Educação Nacional (LDB) (BRASIL, 1996), classes, escolas ou serviços especializados devem realizar atendimento educacional sempre que as condições específicas dos alunos não possibilitarem a sua integração nas classes comuns de ensino regular. Com a aprovação da LDB em 1996, a educação especial passa a ser discutida na prática, porque consolidada como parte da educação da rede regular, dando a esses alunos o direito de permanecer dentro das escolas regulares com maior apoio. 
Figura 1 - Dados do censo escolar 2016
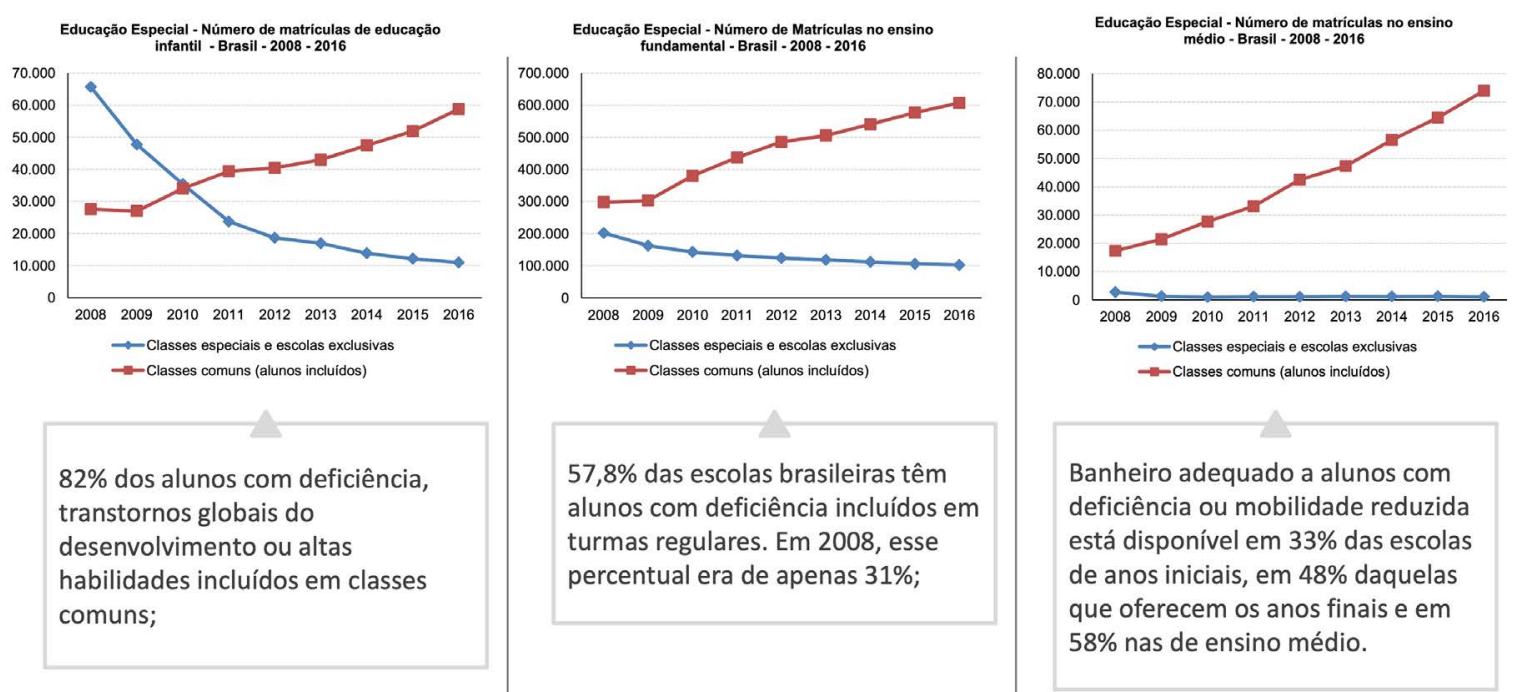

Banheiro adequado a alunos com deficiência ou mobilidade reduzida está disponível em $33 \%$ das escolas de anos iniciais, em $48 \%$ daquelas que oferecem os anos finais e em $58 \%$ nas de ensino médio.

Fonte: Instituto Nacional de Estudos e Pesquisas Educacionais Anísio Teixeira (2019).

O avanço na inclusão, notado no aumento do percentual de matrículas em 2016 demonstrado pelo Censo 2016 necessita ter continuidade. Conforme as propostas buscadas no Plano Nacional da Educação (PNE) (BRASIL, 2014a), previsto para ser colocado em prática a partir de 2014, os educadores distinguiram a educação especial como uma das metas da educação brasileira considerando-a fundamental para que a educação do Brasil avance, pois há muito por fazer para a inclusão de todos na escola. O PNE reforça a importância de haver esforços do governo para atender às necessidades educacionais na perspectiva da inclusão educacional como ponto importante do direito dos alunos especiais uma vez que "[...] há ainda um grande desafio para promover a universalização, com acessibilidade ao ambiente físico e aos recursos didáticos e pedagógicos”. (BRASIL, 2014a, p. 25).

Portanto, as escolas da rede regular de ensino devem matricular estes alunos, oferecendo serviços especializados para atender as peculiaridades de cada um, apresente ele deficiência, transtornos ou altas habilidades, ou não. As dificuldades para conseguir atendimento especializado existem, como necessidade de contratação de profissionais intérprete de LIBRAS (Língua Brasileira de Sinais) para deficientes auditivos, além de pedagogos, psicopedagogos ou outros profissionais que possam acompanhar os alunos, especialmente em casos de auxílio ao deslocamento de alunos com deficiência física e às necessidades básicas de cada pessoa.

Além disto, desde o nascimento, a família pode buscar oportunidades de integrar a criança na sociedade, uma vez que o poder público tem possibilidades legais de oferecer apoio, 
considerando dificuldades financeiras e de deslocamento, escolaridade baixa, entre outros processos relacionados à condição de vida da família. A falta de informação da família é uma das grandes dificuldades na inclusão e a participação da família na vida escolar deste aluno é de suma importância para o processo de inclusão. Já na escola, um aspecto relevante é a necessidade de se modificarem os métodos de ensino e de buscar recursos específicos que favoreçam o aprendizado, atendendo às diferentes necessidades destes alunos. A LDB (BRASIL, 1996) dedica um capítulo à Educação Especial e preconiza que:

Art. 59. Os sistemas de ensino assegurarão aos educandos com deficiência, transtornos globais do desenvolvimento e altas habilidades ou superdotação:

I - currículos, métodos, técnicas, recursos educativos e organização específicos, para atender às suas necessidades [...] (BRASIL, 1996).

Assim, nota-se que na própria LDB está expressa preocupação com os recursos educativos a serem utilizados no ensino, os quais podem conter ajustes como serem escritos em braile para alunos com necessidade visual, propiciarem o ensino com a Língua Brasileira de Sinais (LIBRAS), para as dificuldades dos não ouvintes ou, ainda, terem adaptações para a as necessidades intelectuais, entre outras, colaborando com o desenvolvimento de metodologias que facilitem o aprendizado. Ter estes recursos para as diferentes disciplinas que compõem o currículo escolar é um desafio, pois precisam ser elaborados ou propostos com criatividade, dedicação aos aspectos pedagógicos e específicos da área e atendimento das necessidades dos educandos na educação especial.

Outra preocupação presente na prática educativa está relacionada à formação dos docentes. Por exemplo, o Capítulo 3 do Decreto $n^{\circ} 5.626 / 05$ que regulamenta a Lei $\mathrm{n}^{\circ}$ 10.436/02 (BRASIL, 2005) que reconhece como meio legal de expressão e comunicação a Língua Brasileira de Sinais (Libras) apresenta em seus artigos $4^{\circ}$ e $5^{\circ}$ a necessidade de formação em nível superior de docentes para o ensino de Libras que atuarão na educação infantil, fundamental, média e na educação superior. Este decreto dispõe que a Libras deve ser inserida no currículo dos cursos de formação de professores na forma de disciplina obrigatória para o exercício do magistério, com a contratação de professores para este exercício, ou seja, a legislação impõe a necessidade de todas as instituições de ensino possuirem profissionais especializados na área, preparando a escola para receber os alunos surdos ou com deficiência auditiva por direito, além de referir a necessidade de recursos didáticos para apoiar a educação de tais estudantes (BRASIL, 2005).

A oferta de recursos didáticos variados nas escolas parece escassa e sua presença torna-se fundamental para que se efetive a inclusão. Assim, o objetivo da pesquisa relatada neste artigo foi investigar estudos acadêmicos que desenvolvam materiais didáticos voltados para o ensino de Ciências Biológicas, uma vez que, nesta área, o uso de modelos e outros recursos colabora para aprendizagem significativa dos alunos. Neste relato, as expressões "recursos didáticos" e "materiais didáticos" são usadas como sinônimos.

É importante que os professores estejam capacitados a dar aula utilizando recursos variados para alunos por meio de cursos especializados e vivências, havendo atenção às necessidades específicas de cada aluno, ajudando-os em uma inclusão que se dedique à aprendizagem na escola, e na sociedade, por consequência. 
Logo, é tido como direito materiais e também métodos específicos para cada aluno deficiente, formação de professores especializados em atendê-los, integração na sociedade, nos meios de trabalho e apoio do governo às instituições que possuem alunos deficientes. Segundo as diretrizes da Política Nacional de Educação Especial na Perspectiva da Educação Inclusiva, "Os sistemas de ensino devem organizar as condições de acesso aos espaços, aos recursos pedagógicos e à comunicação que favoreçam a promoção da aprendizagem e a valorização das diferenças" (BRASIL, 2008, p. 13).

A falta de materiais educativos apropriados às escolas que possuem tais alunos em salas regulares, entre outros motivos, dificulta a efetivação da inclusão, na prática. Ainda que tenham sido elaborados, cabe aos professores apropriarem-se destes materiais em sua metodologia de ensino, ajustando-os aos processos de aprendizagem dos conteúdos escolares em sala de aula. Pode-se supor outros motivos para esta dificuldade, tais como: falta de preparação de professores para a inclusão, necessidade de mais programas e trabalhos com a sociedade na inclusão de pessoas com deficiência, transtornos globais do desenvolvimento e altas habilidades, ações que colaborem para sua inclusão no mercado de trabalho, e, de forma geral, condições para a implantação de políticas públicas de apoio a inclusão nas diferentes esferas da sociedade.

Paulino, Vaz e Bazon (2011, p. 678), ao estudarem recursos para inclusão de alunos com deficiência visual, afirmam que:

[...] a intervenção educativa e a utilização de materiais didáticos adaptados às necessidades perceptuais de estudantes com deficiência visual ajudam no desenvolvimento de caminhos alternativos de desenvolvimento com o uso de recursos que favorecem a percepção tátil e a diferenciação de estruturas de forma a facilitar a compreensão do conteúdo tanto por alunos videntes, quanto com deficiência visual.

Assim, dependendo de como são elaborados e utilizados metodologicamente pelos professores, os recursos didáticos adaptados favorecem a aprendizagem de todos, uma vez que se tornam capazes de contextualizar, de maneira didática, o conteúdo escolar, democratizando os conhecimentos na sociedade em que o aluno está incluído.

Um termo que vem sendo utilizado de maneira crescente nos últimos anos é o da Tecnologia Assistiva. Criado em 1988 nos Estados Unidos e presente no Brasil, é assim definido no documento oficial Tecnologia assistiva (BRASIL, 2009, p. 9):

Tecnologia Assistiva é uma área do conhecimento, de característica interdisciplinar, que engloba produtos, recursos, metodologias, estratégias, práticas e serviços que objetivam promover a funcionalidade, relacionada à atividade e participação de pessoas com deficiência, incapacidades ou mobilidade reduzida, visando sua autonomia, independência, qualidade de vida e inclusão social.

A tecnologia assistiva engloba desde a criação de utensílios que ajudem no dia-a-dia da pessoa com deficiência, às adequações físicas de espaços, adequação de computadores ou instrumentos que auxiliem na comunicação aumentativa. Por exemplo, no ensino de Ciências, na área de Química, Benite et al. (2017), propõem o uso da tecnologia assistiva em experimento 
sobre a extração do café envolvendo o conceito de temperatura. Neste experimento, demonstra a utilização de um termômetro vocalizador capaz de emitir um som do valor indicado, para auxílio no aprendizado de pessoas com necessidades visuais.

Diversos estudos têm sido realizados a fim de encontrar metodologias de ensino diferenciadas para que a inclusão se efetive na prática docente em sala de aula. Porém, na área de ensino de Ciências, não se tem claro se os avanços no conhecimento acadêmico englobam estudos relacionados ao ensino de Ciências Biológicas, e cabe saber o que vem sendo publicado em revistas e plataformas acadêmicas.

A importância da discussão sobre o ensino de Ciências Biológicas e sua valorização se insere no campo das "[...] discussões sobre a natureza e importância da alfabetização em geral e da científica, em particular, atingem desde pesquisadores, trabalhando isoladamente, até instituições do porte e escopo da UNESCO [...]” (KRASILCHIK, 1992, p. 6). Pozo e Gómez Crespo (2009, p. 23) apresentam a ciência como saber histórico e mutável, a ser construído, assim como o aluno constrói seus conhecimentos quando as propostas de ensino priorizam seu processo construtivo em sala de aula.

Relacionado à importância do ensino de Ciências Biológicas, destaca-se:

Para que um país esteja em condições de satisfazer as necessidades fundamentadas da sua população, o ensino das ciências e a tecnologia é um imperativo estratégico. Como parte dessa educação, os estudantes deverão aprender a resolver problemas concretos e a satisfazer as necessidades da sociedade, utilizando as suas competências e conhecimentos científicos e tecnológicos. (UNESCO, 1999, tradução nossa)2 .

Neste sentido, Cachapuz et al. (2005, p. 211) destacam os desafios das modificações metodológicas, as quais, nas pesquisas em ensino de Ciências, têm origem na investigação em torno dos problemas de ensino e aprendizagem das ciências. As pesquisas, que acarretam outros arranjos metodológicos em aula, valorizam "[...] uma proposta efetiva dos estudantes na construção de conhecimentos e, marcadamente, de índole sócioconstrutivista”.

No ensino de Ciências Biológicas são desenvolvidos conteúdos que abordam a natureza macroscópica e microscópica dos seres vivos e suas estruturas. A fim de auxiliar no processo de aprendizagem de ambas, tem-se como opção o uso de recursos didáticos que ampliam as estruturas e permitem seu tateamento, tais como modelos que buscam estimular a reflexão em torno da tridimensionalidade das estruturas, dos componentes, dos ciclos e afins, presentes no conteúdo das Ciências Biológicas. Para Ceccantini (2006) a aprendizagem de botânica recorre ao uso de imagens de base bidimensional, como desenhos de cortes ou fotos, porém é baixa a compreensão de estruturas espacialmente, pois os alunos tendem a descrever as células

\footnotetext{
${ }^{2}$ No original: "Para un país que quiere estar en condiciones de atender las necesidades fundamentales de su población, la enseñanza de la ciencia y la tecnología es un imperativo estratégico. Como parte de esa educación, los estudiantes deberán aprender a resolver problemas concretos y a atender las necesidades de la sociedad utilizando sus competencias y conocimientos científicos y tecnológicos".
} 
como círculos e não esferas. Segundo o autor, o alto preço e os erros dificultam o uso didático de modelos didáticos prontos pelos professores, os quais, com determinação e criatividade, podem confeccioná-los para o ensino. A utilização de recursos didáticos tridimensionais enriquece a aula e estimula o aluno de maneira simples e acessível aos professores, que pode buscar apoio em investigações sobre o tema.

Considerando o recurso didático importante ferramenta para o ensino e aprendizagem, logo, o presente estudo tem como preocupação agrupar e analisar investigações dedicadas a elaboração de materiais, pois estas buscam, na investigação, propor materiais sugerindo e atendendo critérios didáticos, lógicos, entre outros, com o rigor conceitual para confiabilidade no uso por professores. Buscam-se recursos didáticos já existentes que alcancem as necessidades de pessoas com necessidades especiais, procurando igualá-las nas oportunidades de aprendizado e a inclusão na prática.

\section{Objetivos}

Analisar a diversidade dos materiais propostos em estudos acadêmicos como recursos didáticos no ensino de Ciências Biológicas (ou Biologia) visando apoiar a aprendizagem de alunos com deficiência em revistas e plataformas de pesquisas acadêmicas, como Google e sites de bibliotecas de universidades na internet.

\section{Material e Métodos}

Realizou-se uma revisão bibliográfica relativa a artigos do período de 2007 a 2016 sobre uso de materiais didáticos no ensino de Ciências Biológicas (ou Biologia) para alunos com deficiência, transtornos globais do desenvolvimento e altas habilidades, e o papel destas ferramentas na inclusão dos alunos, considerando o público almejado em cada publicação selecionada para análise. Foram consultadas as seguintes revistas em suas plataformas da internet ou por meio da base de dados Scielo ${ }^{3}$ :

- Caderno de Pesquisa;

- Cadernos PDE (Programa de Desenvolvimento Educacional);

- Ciência \& Educação;

- Educação e Pesquisa;

- Educação e Sociedade;

- Educação em Revista;

- Revista Brasileira de Educação Especial;

- Revista Brasileira de Educação;

- Revista Brasileira de Estudos Pedagógicos

- Revista Brasileira de Pesquisa em Educação em Ciências;

\footnotetext{
${ }^{3}$ Disponível em: http://www.scielo.org/. Acesso em: 23 abr. 2019.
} 
- Revista da SBEnBio: revista da Associação Brasileira de Ensino de Biologia;

- Revista Eletrônica: debates em educação científica e tecnológica.

Foram realizadas consultas a 16 bases de dados, incluindo as revistas citadas, as bases das bibliotecas virtuais de universidades públicas paulistas (USP, UNESP e Unicamp), o buscador do Google. Foi consultado também o Portal EduCapes da Coordenação de Aperfeiçoamento de Pessoal de Nível Superior (CAPES), um repositório de diversos materiais didáticos (imagens, vídeos, animações e jogos, entre outros), além de publicações como artigos.

O Portal EduCapes ${ }^{4}$ foi consultado para buscar publicações de artigos na área de ensino de Ciências que se referissem aos recursos didáticos voltados ao ensino de Ciências Biológicas, preparados para uso com alunos com deficiência. Este portal permite que se consulte por palavras-chave as quais, ao serem digitadas tal como nas revistas, não atendiam ao filtro pretendido. Porém, ao se realizar este procedimento, trabalhos de diferentes temáticas não relacionadas à inclusão foram elencados pelo próprio buscador do Portal. Deste modo, optou-se por não incluí-lo no mapeamento. Além disto, como se trata de um repositório, as publicações resultantes estavam presentes nas revistas e eventos onde originalmente devem ter sido publicadas.

Para encontrar os artigos foram escolhidas as palavras-chaves: Inclusão, Biologia, Deficiência, Recurso e Tecnologia Assistiva. Tais palavras eram incluídas nos buscadores dos sites das próprias revistas, colocadas isoladamente e em combinação, duas a duas, para averiguação.

Após a busca conferiu-se, pela leitura, se os títulos e resumos abordavam a área de Biologia e a inclusão. Os que não se encaixavam neste critério ou se referiam a pesquisas realizadas em outros países ou ainda estavam em outro idioma que não a língua portuguesa foram excluídos da amostra.

Em cada artigo encontrado, procurou-se analisar o recurso didático utilizado da seguinte forma: identificação dos objetivos propostos pelos autores, deficiências indicadas (visual, motora, auditiva ou cognitiva) e o conteúdo abordado do material didático proposto de maneira a obter-se tabela comparativa de materiais.

\section{Resultados e discussão}

Foi realizado levantamento de artigos sobre o ensino de Ciências Biológicas com propostas de materiais didáticos em 12 revistas consultadas em plataformas digitais, bibliotecas virtuais de três universidades do país e arquivo do Google, publicadas entre os anos de 2007 a 2016. As revistas que continham artigos na temática e atendiam a busca pelas palavras-chave indicadas foram as seguintes:

\footnotetext{
${ }^{4}$ Disponível em: https://educapes.capes.gov.br/. Acesso em: 23 abr. 2019.
} 
- Revista da SBEnBio: artigos 3, 5, 6, 7, 8, 9, 10, 11 e 12;

- Revista Brasileira de Pesquisa em Educação em Ciências: artigo 1;

- Revista Eletrônica: debates em educação científica e tecnológica: artigo 2;

- Biblioteca Virtual da UNESP: artigo 13;

- buscador Google: seleção de apresentações em seminários e congressos disponíveis na internet: artigos 4, 14, 15, 16 e 18;

- Cadernos PDE: artigo 17.

Foram encontrados 18 artigos acadêmicos relacionados aos recursos didáticos apropriados a educação inclusiva voltados ao ensino de Ciências Biológicas listados no quadro 1.

Quadro 1 - Relação de trabalhos acadêmicos encontrados sobre recursos didáticos apropriados a educação inclusiva em Biologia

\begin{tabular}{|c|c|c|c|c|c|}
\hline $\begin{array}{c}\mathbf{N}^{\circ} \\
\text { Artigo }\end{array}$ & Autor(es) e Título & Referência & $\begin{array}{c}\text { Tipo de } \\
\text { Necessidade }\end{array}$ & Assunto & Ano \\
\hline 1 & $\begin{array}{l}\text { PAULINO, A. L. S. ; VAZ, } \\
\text { J. M. C.; BAZON, F. V. M. } \\
\text { Materiais adaptados para } \\
\text { ensino de biologia como } \\
\text { recursos de inclusão de alunos } \\
\text { com deficiência visual. }\end{array}$ & $\begin{array}{l}\text { In: ENCONTRO } \\
\text { DA ASSOCIAÇÃO } \\
\text { BRASILEIRA DE } \\
\text { PESQUISADORES } \\
\text { EM EDUCAÇÃO } \\
\text { ESPECIAL, 7., 2011, } \\
\text { Londrina. }\end{array}$ & Visual & $\begin{array}{l}\text { Célula } \\
\text { eucariótica } \\
\text { animal, tradução } \\
\text { e núcleo celular. }\end{array}$ & 2011 \\
\hline 2 & $\begin{array}{l}\text { LOPES, N. R.; ALMEIDA, L. } \\
\text { A.; AMADO, M. V. Produção } \\
\text { e análise de recursos didáticos } \\
\text { para ensinar alunos com } \\
\text { deficiência visual o conteúdo } \\
\text { de mitose: uma pratica } \\
\text { pedagógica no ensino de } \\
\text { ciências biológicas. }\end{array}$ & $\begin{array}{l}\text { Debates em } \\
\text { Educação Científica e } \\
\text { Tecnológica, Vitória, } \\
\text { v. 2, n. 2, dez. } 2012 \text {. }\end{array}$ & Visual & Mitose. & 2012 \\
\hline 3 & $\begin{array}{l}\text { GOYA, P. R. L. et al. Materiais } \\
\text { didáticos de ciências e biologia } \\
\text { para alunos com necessidades } \\
\text { educacionais especiais ou } \\
\text { design e educação: projeto } \\
\text { de um material didático para } \\
\text { deficientes visual. }\end{array}$ & $\begin{array}{l}\text { Revista da SBEnBio, } \\
\text { Niterói, n. 7, p. 6173- } \\
\text { 6184, } 2014 .\end{array}$ & $\begin{array}{l}\text { Visual / } \\
\text { Intelectual }\end{array}$ & $\begin{array}{l}\text { Ecologia, teia } \\
\text { alimentar, Leis } \\
\text { de Mendel, } \\
\text { Astronomia e } \\
\text { fases da lua. }\end{array}$ & 2014 \\
\hline 4 & $\begin{array}{l}\text { ALVES JUNIOR, C. A. } \\
\text { et al. Desenvolvimento de } \\
\text { material didático para o ensino } \\
\text { de ciências a estudantes } \\
\text { deficientes visuais. }\end{array}$ & $\begin{array}{l}\text { In: COLÓQUIO } \\
\text { LUSO-BRASILEIRO } \\
\text { DE EDUCAÇÃO, 2., } \\
\text { 2016, Joinville. }\end{array}$ & Visual & $\begin{array}{l}\text { Kit laboratorial } \\
\text { com descrições } \\
\text { em braille. }\end{array}$ & 2016 \\
\hline
\end{tabular}

continua 
Stella, L. F.; Massabni, V. G.

Quadro 1 - Relação de trabalhos acadêmicos encontrados sobre recursos didáticos apropriados a educação inclusiva em Biologia

\begin{tabular}{|c|c|c|c|c|c|}
\hline $\begin{array}{c}\mathrm{N}^{\circ} \\
\text { Artigo }\end{array}$ & Autor(es) e Título & Referência & $\begin{array}{c}\text { Tipo de } \\
\text { Necessidade } \\
\end{array}$ & Assunto & Ano \\
\hline 5 & $\begin{array}{l}\text { RIBAS, C. P. et al. Materiais } \\
\text { alternativos para alunos cegos } \\
\text { no ensino de ciências. }\end{array}$ & $\begin{array}{l}\text { In: ENCONTRO } \\
\text { REGIONAL SUL } \\
\text { DE ENSINO DE } \\
\text { BIOLOGIA, 6., 2013, } \\
\text { Santo Angelo. }\end{array}$ & Visual & $\begin{array}{l}\text { Tabela periódica, } \\
\text { estrutura de } \\
\text { moléculas, } \\
\text { espelhos } \\
\text { côncavos, } \\
\text { grandezas } \\
\text { vetoriais, } \\
\text { divisão celular } \\
\text { e estruturas } \\
\text { vegetais. }\end{array}$ & 2013 \\
\hline 6 & $\begin{array}{l}\text { SILVA, P. R.; RUST, N. M. } \\
\text { Ensino de ciências: produção } \\
\text { de material didático para } \\
\text { alunos cegos e com baixa } \\
\text { visão. }\end{array}$ & $\begin{array}{l}\text { Revista da SBEnBio, } \\
\text { Niterói, n. 9, p. 2021- } \\
\text { 2033, 2016. }\end{array}$ & Visual & $\begin{array}{l}\text { Sistema } \\
\text { respiratório. }\end{array}$ & 2016 \\
\hline 7 & $\begin{array}{l}\text { FERNANDES, A. F. F.; } \\
\text { LAGE, D. A. Inclusão } \\
\text { escolar no ensino de biologia: } \\
\text { elaboração de materiais } \\
\text { adaptados para deficientes } \\
\text { visuais e auditivos. }\end{array}$ & $\begin{array}{l}\text { Revista da SBEnBio, } \\
\text { Niterói, n. 9, p. 4920- } \\
\text { 4931, 2016. }\end{array}$ & $\begin{array}{l}\text { Visual / } \\
\text { Auditiva }\end{array}$ & $\begin{array}{l}\text { Árvores, } \\
\text { artrópodes, } \\
\text { genitália } \\
\text { feminina e } \\
\text { insetos. }\end{array}$ & 2016 \\
\hline 8 & $\begin{array}{l}\text { BASSO, S. P. S. et al. Material } \\
\text { didático multissensorial: a } \\
\text { fecundação para deficientes } \\
\text { visuais. }\end{array}$ & $\begin{array}{l}\text { Revista da SBEnBio, } \\
\text { Niterói, n. 5, } 2012 .\end{array}$ & Visual & Fecundação. & 2012 \\
\hline 9 & $\begin{array}{l}\text { LIAÑO, G. A.; SANTOS, } \\
\text { L. D.; VARANDA, L. L. } \\
\text { Genética ao alcance das mãos: } \\
\text { confecção e utilização de } \\
\text { modelos táteis para a inclusão } \\
\text { de alunos com deficiência } \\
\text { visual no ensino regular. }\end{array}$ & $\begin{array}{l}\text { Revista da SBEnBio, } \\
\text { Niterói, n. 9, } 2016 .\end{array}$ & Visual & Genética. & 2016 \\
\hline 10 & $\begin{array}{l}\text { MENEZES, J. B. F.; NEVES, } \\
\text { L.; NUNES, N. Educação } \\
\text { inclusiva no ensino de } \\
\text { biologia: experiência no estágio } \\
\text { supervisionado. }\end{array}$ & $\begin{array}{l}\text { Revista da SBEnBio, } \\
\text { Niterói, n. 9, } 2016 .\end{array}$ & Visual & $\begin{array}{l}\text { Bactérias e } \\
\text { protozoários. }\end{array}$ & 2016 \\
\hline 11 & $\begin{array}{l}\text { PAULETTI, J. et al. Modelo } \\
\text { didático tridimensional } \\
\text { de epiderme foliar como } \\
\text { estratégia para inclusão de } \\
\text { alunos com deficiência visual } \\
\text { no ensino de botânica. }\end{array}$ & $\begin{array}{l}\text { Revista da SBEnBio, } \\
\text { Niterói, n. 7, } 2014 .\end{array}$ & Visual & Epiderme foliar. & 2014 \\
\hline
\end{tabular}


Quadro 1 - Relação de trabalhos acadêmicos encontrados sobre recursos didáticos apropriados a educação inclusiva em Biologia

\begin{tabular}{|c|c|c|c|c|c|}
\hline $\begin{array}{c}\mathrm{N}^{\circ} \\
\text { Artigo }\end{array}$ & Autor(es) e Título & Referência & $\begin{array}{c}\text { Tipo de } \\
\text { Necessidade }\end{array}$ & Assunto & Ano \\
\hline 12 & $\begin{array}{l}\text { CARVALHO, P. M. S.; SILVA, } \\
\text { F. A. Horta orgânica como } \\
\text { ambiente de aprendizagem } \\
\text { de educação ambiental para } \\
\text { alunos com deficiência } \\
\text { intelectual. }\end{array}$ & $\begin{array}{l}\text { Revista da SBEnBio, } \\
\text { Niterói, n. 7, } 2014 .\end{array}$ & Intelectual & $\begin{array}{l}\text { Ecologia. } \\
\text { Educação } \\
\text { ambiental. } \\
\text { Outros. }\end{array}$ & 2014 \\
\hline 13 & $\begin{array}{l}\text { FLORES, A. S. Recursos } \\
\text { didáticos direcionados como } \\
\text { complemento ao ensino de } \\
\text { biologia para professores com } \\
\text { deficiência visual: um estudo } \\
\text { de caso. }\end{array}$ & $\begin{array}{l}\text { Trabalho de conclusão } \\
\text { de curso (Bacharelado } \\
\text { em ciências biológicas) } \\
\text { - Faculdade de } \\
\text { Engenharia de Ilha } \\
\text { Solteira, Universidade } \\
\text { Estadual Paulista, } \\
2016 .\end{array}$ & Visual & $\begin{array}{l}\text { Fotossíntese e } \\
\text { células. }\end{array}$ & 2016 \\
\hline 14 & $\begin{array}{l}\text { PIRES, B. B. M.; JORGE, } \\
\text { V. L. Confecção de modelos } \\
\text { biológicos para alunos cegos } \\
\text { no segundo segmento. }\end{array}$ & $\begin{array}{l}\text { In: SEMINÁRIO } \\
\text { INTERNACIONAL } \\
\text { DE INCLUSÃO } \\
\text { ESCOLAR, 1., 2014, } \\
\text { Rio de Janeiro. }\end{array}$ & Visual & $\begin{array}{l}\text { Mitose, célula } \\
\text { animal, célula } \\
\text { vegetal e } \\
\text { tradução } \\
\text { RNAm. }\end{array}$ & 2014 \\
\hline 15 & $\begin{array}{l}\text { VIDAL, M. D.; CARGIN, } \\
\text { A. B.; DALLABONA, K. } \\
\text { G. Ensino de ciências e } \\
\text { a deficiência visual: uma } \\
\text { proposta de atividade para o } \\
\text { estudo do corpo humano. }\end{array}$ & $\begin{array}{l}\text { CONGRESSO } \\
\text { INTERNACIONAL } \\
\text { ABED DE } \\
\text { EDUCAÇÃO A } \\
\text { DISTÂNCIA, 2016, } \\
\text { Blumenau. } \\
\end{array}$ & Visual & $\begin{array}{l}\text { Órgãos do } \\
\text { corpo humano. }\end{array}$ & 2016 \\
\hline 16 & $\begin{array}{l}\text { OLIVEIRA, T. G. C.; } \\
\text { MARQUES, R. C. P. Utilização } \\
\text { de modelos didáticos no } \\
\text { ensino de biologia e o } \\
\text { processo de inclusão na cidade } \\
\text { de Apodi, RN. }\end{array}$ & $\begin{array}{l}\text { In: CONEDU, 3., } \\
\text { 2016, Campina } \\
\text { Grande. }\end{array}$ & $\begin{array}{l}\text { Visual / } \\
\text { Intelectual }\end{array}$ & Células. & 2016 \\
\hline 17 & $\begin{array}{l}\text { BEZ, J. J. V. O } \\
\text { desenvolvimento da } \\
\text { aprendizagem da célula em } \\
\text { modelos didáticos táteis para } \\
\text { alunos cegos e de baixa visão. }\end{array}$ & $\begin{array}{l}\text { Curitiba: Secretaria } \\
\text { Estadual da Educação, } \\
\text { 2013. (Cadernos PDE, } \\
\text { 2). }\end{array}$ & Visual & $\begin{array}{l}\text { Células, } \\
\text { neurônio, óvulo, } \\
\text { espermatozoide, } \\
\text { hemácia e } \\
\text { leucócito. }\end{array}$ & 2013 \\
\hline 18 & $\begin{array}{l}\text { GOULART, I. B.; MENEZES, } \\
\text { M. F.; CARLOS, J. O jogo dos } \\
7 \text { erros como estratégia para } \\
\text { o ensino das características } \\
\text { celulares para portadores e } \\
\text { não portadores de deficiência } \\
\text { visual. }\end{array}$ & $\begin{array}{l}\text { In: ENCONTRO } \\
\text { DE INICIAÇÃO } \\
\text { CIENTÍFICA E } \\
\text { TECNOLÓGICA } \\
\text { DO IFSP, 2016, } \\
\text { Araraquara. }\end{array}$ & Visual & Células. & 2016 \\
\hline
\end{tabular}

Fonte: elaborado pelas autoras. 
No quadro 1 estão arrolados os 18 artigos encontrados e que são o corpus da pesquisa. Nota-se também (quadro 2) que de 2007 a 2010 não foram encontrados artigos publicados nas revistas investigadas. Por outro lado, em 2016, foram encontrados nove artigos. Esta constatação indica que a atenção ao tema na área de Ensino de Ciências Biológicas se deu após 2010. Este aspecto é positivo na medida em que revela maior preocupação dos pesquisadores com o tema, a ponto de desenvolverem na forma de pesquisa a proposição de novos materiais didáticos. É também relevante pois, embora sejam apenas 18 estudos, apresentam materiais com conteúdos específicos para atender ao currículo escolar na área de Biologia.

Quadro 2 - Número de artigos por ano, entre 2007 e 2016

\begin{tabular}{|c|l|c|l|}
\hline Ano & Quantidade & Ano & Quantidade \\
\hline 2007 & 0 & 2012 & 2 \\
\hline 2008 & 0 & 2013 & 2 \\
\hline 2009 & 0 & 2014 & 4 \\
\hline 2010 & 0 & 2015 & 0 \\
\hline 2011 & 1 & 2016 & 9 \\
\hline
\end{tabular}

Fonte: elaborado pelas autoras.

Ao analisar os títulos dos artigos e materiais didáticos propostos por cada um deles, percebeu-se que poderiam abranger mais conteúdos e propostas. E se, de fato, “[...] existem diferentes propostas de recursos didáticos para o trabalho com inclusão no ensino de Ciências Biológicas estudados nos últimos anos, evidenciando assim maior interesse dos profissionais da área pelo assunto” (SILVA; LANDIN, 2014, p. 34), o que pode levar, conforme Nepomuceno (2015, p. 54) a uma "[...] nova perspectiva nos estudos sobre a inclusão de pessoas com deficiência”, nem todas as propostas existentes estão sendo publicadas em revistas dedicadas à pesquisa acadêmica.

Nos conteúdos abordados são encontrados os assuntos: Genética (mitose/meiose, processo de tradução, organelas das células animais e vegetais, núcleo celular, lei de Mendel e moléculas), Reprodução (fecundação e órgãos reprodutivos), Astronomia (fases da lua), Ecologia (teia alimentar e artrópodes), Laboratório (kit laboratorial), Botânica (estruturas vegetais, fotossíntese e meios de produção agrícola) e corpo humano (sistema respiratório, neurônio, hemácia, leucócito e órgãos do corpo), sendo alguns assuntos estudados no Ensino Fundamental e outros, no Ensino Médio.

O conteúdo de célula, presente em geral no Ensino Médio, é recorrente: foram encontrados sete trabalhos, em 18, que tratavam especificamente de recurso didático para o ensino de célula (Figura 2). Outros artigos não tratavam especificamente de célula ou sua diferenciação e caracterização, mas dependiam deste conteúdo para serem compreendidos (Figura 3). Como exemplificação, o trabalho oito (Figura 4), sobre fecundação e o trabalho 11 (Figura 5), sobre epiderme foliar, se dedicam a propor recursos para conteúdos que dependem da estrutura celular ou molecular para sua compreensão e também estão relacionados à compreensão de que os organismos vivos são, basicamente, constituídos de célula, as quais dependem 
de estruturas moleculares para manutenção da vida. Foram selecionados os exemplos a seguir, como ilustração:

Figura 2 - Recursos didáticos para ensino do tema "Célula"
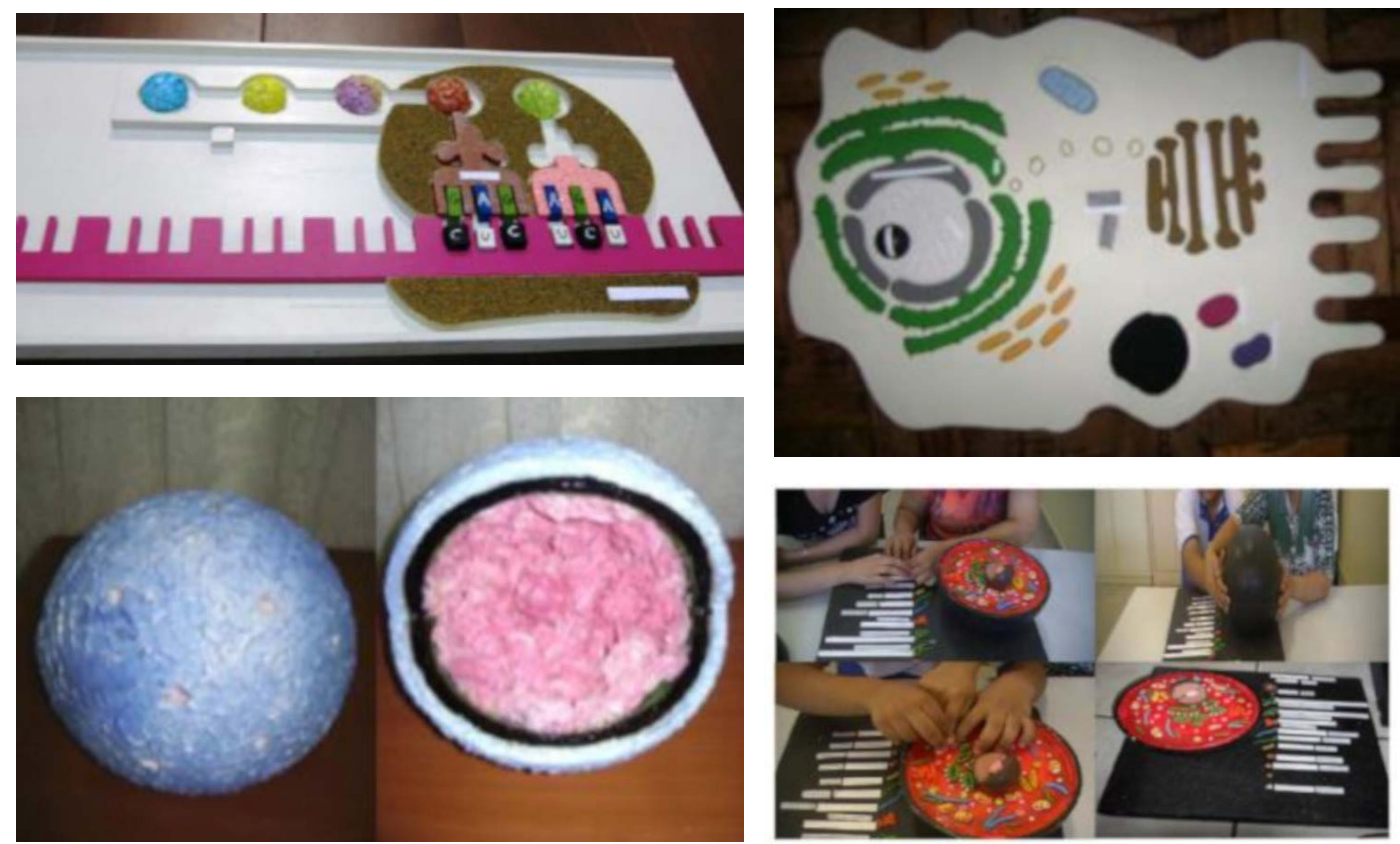

Fontes: Paulino, Vaz e Bazon (2011, p. 676) e Flores (2016, p. 99).

Estes modelos sobre células foram elaborados com materiais de baixo custo, cores fortes e texturas diferentes, ajustes didáticos que favorecem a educação inclusiva. Porém, o Trabalho 1 apresenta maior diferenciação e possibilidade de interação que os demais, uma vez que os estudantes devem mudar de local as peças componentes do modelo. Os outros trabalhos também são modelos ajustados a aprendizagem de Biologia de estudantes cegos e com baixa visão, pois permitem que passem as mãos e sintam diferentes texturas e relevos das estruturas. 
Stella, L. F.; Massabni, V. G.

Figura 3 - Modelo tátil para ensino do tema "Mitose"

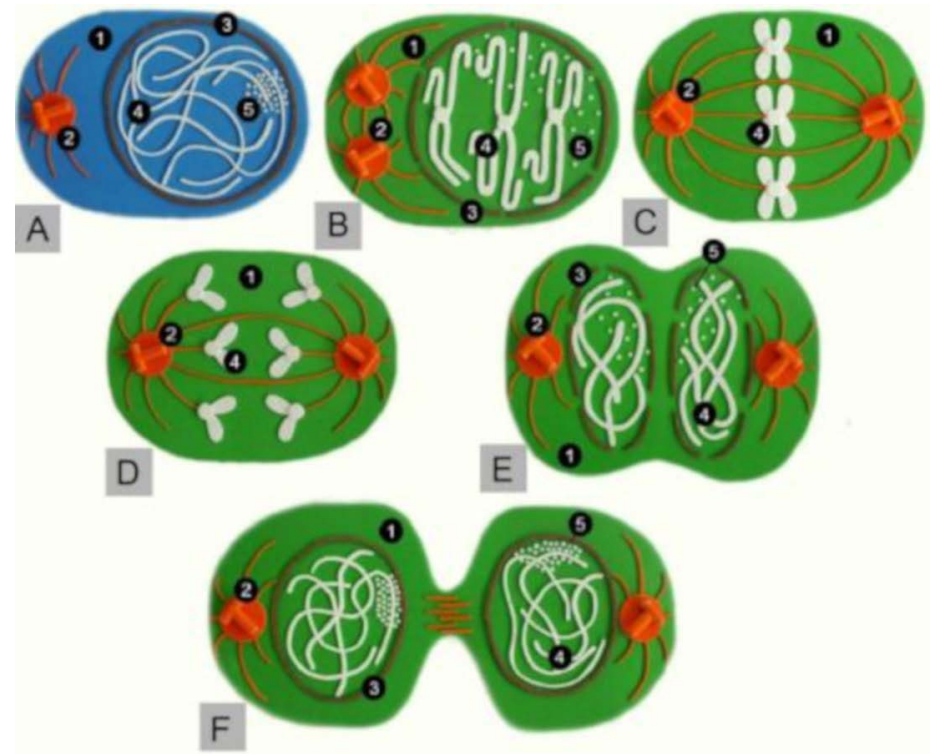

Fonte: Lopes, Almeida e Amado (2012).

O material didático da figura 3 foi produzido com barbantes, EVA, lixa e bijuterias. O estudante cego e de baixa visão, assim como os demais, deve tocar e sentir as diferentes texturas e relevos, ação que colabora na aprendizagem das fases da mitose.

Figura 4 - Recurso didático para ensino do tema "Fecundação"
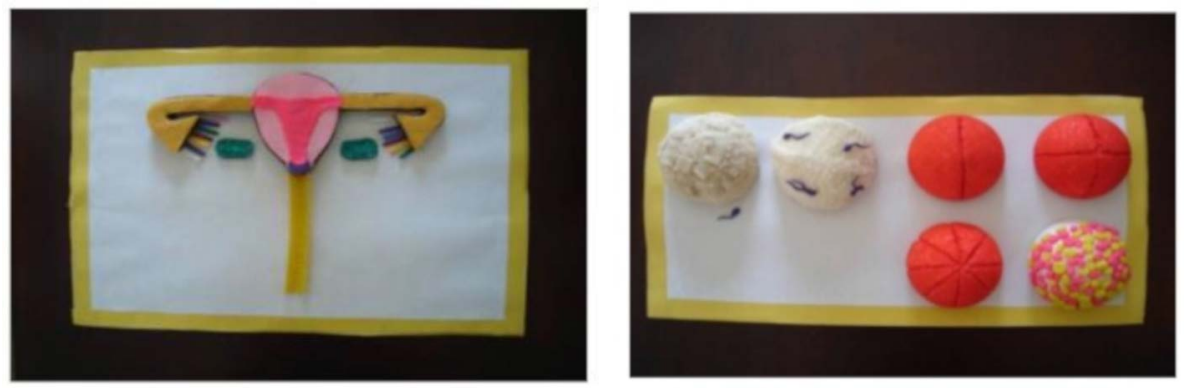

Fonte: Basso et al. (2012).

Os modelos da figura 4 foram produzidos com bexigas, biscuit, tintas e pano, tornando-se capaz de auxiliar a demonstração, para o aluno, por meio do toque também, as diferenças 
entre as texturas e localização das estruturas do sistema reprodutor feminino e etapas da fecundação.

Figura 5 - Recurso didático para ensino do tema "Epiderme Foliar"

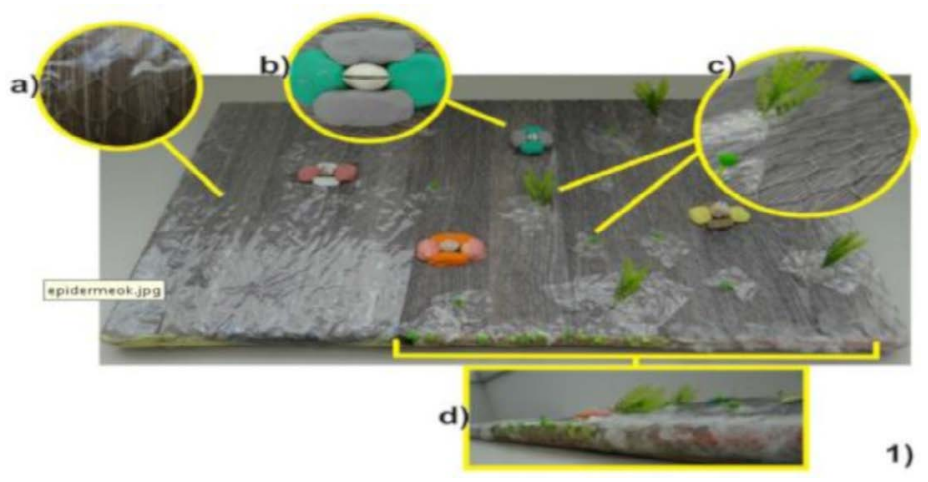

Fontes: Pauletti et al. (2014).

Por fim, este material da figura 5, sobre epiderme vegetal, foi elaborado com cerca, arames, conchas marinhas, isopor, algodão, massinha e ramos de flores artificiais onde, através do toque, o estudante cego ou de baixa visão é capaz de perceber pelo tato as diferentes estruturas que compõem a epiderme foliar. Este e os demais modelos são visualmente atrativos, podendo também favorecer a aprendizagem de alunos videntes.

De modo geral, é possível perceber que os artigos buscam trazer para o campo visual ou tátil estruturas não visíveis a olho nu, evidenciando o aspecto tridimensional destas. Portanto, há preocupação dos autores em elaborar recursos didáticos que tenham como foco os conteúdos tidos como abstratos e possivelmente de compreensão mais difícil aos estudantes.

Somando os trabalhos que se referem especificamente à célula aos demais que se referem a conteúdos microscópicos ou ultramicroscópicos (como as moléculas) nota-se um total de 12 artigos. Portanto, apenas 6 artigos entre os 18 (os de número 3, 4, 6, 7, 12 e 15) abordam conteúdos de natureza macroscópica e, entre estes, os artigos 3, 7 e 12 trazem assuntos relacionados ao meio ambiente e aos vegetais: Ecologia (artigo 3), órgãos das árvores (artigo 7) e horta (artigo 12).

Percebe-se a falta de materiais relacionados a outros assuntos abordados na área de Ciências Biológicas e presentes no currículo escolar, tais como: Genética (processo de transcrição, sistema Rh e hereditariedade, por exemplo), Ecologia, ciclos da natureza, interação fauna e flora, problemas ambientais, por exemplo), Corpo Humano (sistema nervoso, sistema digestório, sistema circulatório, interação entre os sistemas, e hormônio, por exemplo), Botânica (respiração celular, xilema e floema, nutrição das plantas, adubação, por exemplo, conforme o que tradicionalmente é parte do currículo escolar na área de Biologia. Assim, nota-se que temas relacionados aos vegetais e ao meio ambiente estão entre os menos presentes, pois existem menos recursos didáticos estudados nas plataformas acadêmicas e revistas utilizadas no estudo, merecendo investigações para o seu desenvolvimento. 
Sugere-se a criação de novos modelos com orientações para o uso de situações- problema pelo professor, de modo a apoiá- lo metodologicamente sem retirar sua autonomia na elaboração da própria prática. Para as questões ambientais, que fazem parte do conteúdo de Biologia, não foram encontrados recursos didáticos. Estes podem ser planejados, por exemplo, a partir de uma situação-problema, abordando a temática ambiental de maneira transversal baseada na realidade fornecida pelo próprio aluno (TEIXEIRA; SOUZA, 2015), contextualizando-o e facilitando a interdisciplinaridade.

Considerando o proposto por cada autor em seu trabalho e analisando as necessidades especiais apresentadas, do total de 18 artigos, 17 tratam da educação para deficientes visuais, três para deficientes intelectuais, dois para deficientes auditivos e apenas um para deficientes motores como visto no gráfico 1.

Gráfico 1 - Quantidade de publicações acadêmicas encontradas segundo a deficiência/necessidade especial do estudante ${ }^{1}$

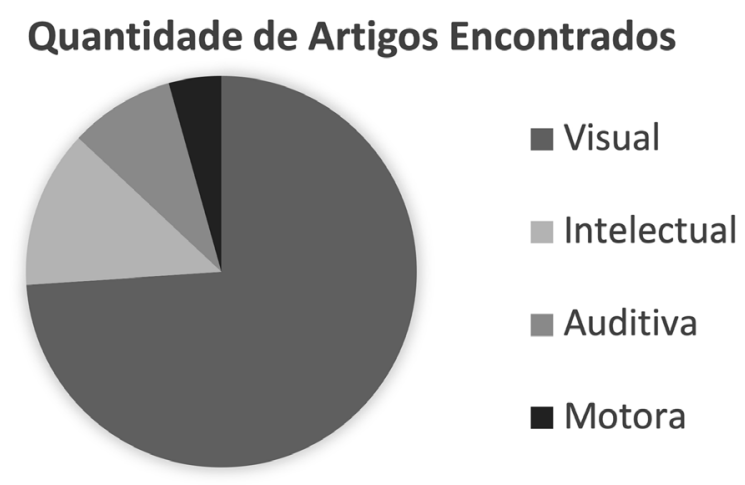

Critérios de análise, segundo as próprias autoras, sobre a necessidade especial que se buscou abordar com o recurso didático proposto. Em alguns artigos, por conta das características do material criado, mais de uma necessidade especial foi abordada.

Fonte: elaborado pelas autoras.

$\mathrm{O}$ artigo relacionado à necessidade motora é o de número 12 , que também está vinculado a todas as outras necessidades especiais, uma vez que trabalha com a implementação de horta em escolas. O trabalho com horta permite valorizar os sentidos dos alunos, se for baseado no planejamento de atividades que requeiram a percepção de estímulos por meio dos cinco sentidos. Por exemplo, permite, ao professor, abordar com os estudantes fatores ambientais como luz e temperatura e alimentação por meio da degustação Se preparadas para envolver estímulos táteis, entre outros, ajusta-se a inclusão de alunos cegos e de baixa visão.

Buscou-se inferir, ao ler os artigos, quais recursos propostos não eram apenas para ilustrar ou para serem observados pelo aluno, favorecendo metodologias de ensino diferenciadas. Nos artigos de número 2, 3, 5, 6, 7, 8, 9, 10,11, 13, 14, 15, 16, 17 e 18 notou-se que era 
possível ou esperada a interação pois observou-se que, nos recursos propostos, o aluno poderia interagir, manuseando, construindo ou mesmo mexendo e modificando o modelo, alterando-o na prática. Buscou-se saber se o recurso proposto dava a possibilidade de o professor utilizá-lo para ir explicando, de forma a ir trocando posições de peças no modelo simulando uma situação dinâmica, que favoreça a compreensão de processos biológicos. Ou ainda, o aluno poderia manipular o recurso, em um processo de análise para construir seus conhecimentos.

Ao analisar o nível de interação aluno-material, utilizou-se como referência o quadro 3.

Quadro 3 - Critérios utilizados para avaliar os níveis de interação e suas características na observação dos recursos didáticos para o ensino de Ciências Biológicas propostos nos artigos da revisão bibliográfica realizada

\begin{tabular}{|l|l|}
\hline \multicolumn{1}{|c|}{ Nível de interação } & \multicolumn{1}{c|}{ Característica } \\
\hline Pouca & Aluno apenas olha ou escuta \\
\hline Média & Aluno toca o material \\
\hline Grande & Aluno toca com a possibilidade de realizar mudanças no material \\
\hline
\end{tabular}

Fonte: elaborado pelas autoras.

No presente trabalho, para avaliar o potencial do material, optou-se por criar e estabelecer critérios relacionados à possibilidade de interação do aluno com o recurso didático, justamente porque materiais que não requerem a interação pouco estimulam o aluno e pouco acrescentam aos recursos existentes como apoio ao ensino tradicional, que não valoriza o aluno ativo. Recursos planejados apenas para observação, como cartazes com esquemas ou figuras, além de não incentivarem a interação manual ou intelectual, são fáceis de serem encontrados, sem se constituírem em um diferencial para o ensino da área de Biologia. Além disto, a possibilidade de o aluno realizar a manipulação e interagir com o material, permite que ele o explore, tire conclusões, tente analisar com sua própria capacidade, o que pode ser auxiliado pelo professor. Assim, torna-se uma atividade que pode colaborar com a ação mental, em especial se o estudante estiver no estágio operatório concreto do desenvolvimento cognitivo. Desta forma, favorece a construção de conhecimentos.

Conforme Andrade e Massabni (2011), por meio da experiência física - realizada pelo aluno quando manipula e testa o objeto, ou realizada pelo professor, no caso de uma demonstração - se retiram dados e se tecem conclusões sobre o mundo natural - que Piaget (1995) chama de abstração empírica.

No levantamento percebeu-se que em 83,33\% do total de 18 artigos, os materiais apresentam médio e alto nível de possibilidade de interação, ou seja, os alunos podem, ou não, tocar e realizar modificações nos materiais, facilitando a aprendizagem de processos e a compreensão de estruturas conforme presente no gráfico 2. Por exemplo, o material do artigo 1 (figura 1) permite a interação uma vez que, para o aluno entender o processo de tradução celular, é preciso que haja movimentação das peças que compõem o material, ou seja, é necessário que haja mudança na estrutura do recurso criado. 
São raros os modelos que permitem muita interação do estudante (artigos 1, 4 e 12), as quais podem facilitar a construção do conhecimento, especialmente quando se trata de operações manuais que embasam construções mentais. Pressupostos teóricos da construção do conhecimento, como os presentes na teoria de Piaget e Inhelder (1982), sugerem que o objeto concreto presente materialmente é necessário nos estágios anteriores ao operatório formal graças à função simbólica presente no estágio nomeado Pré-operatório e ao desenvolvimento de noções de tempo, espaço, velocidade, ordem, entre outras relacionadas à abstração de dados da realidade durante sua passagem pelo estágio operatório-concreto.

Neste sentido, por poderem facilitar a construção de conhecimento entre estudantes com dificuldades intelectuais que perpassam os estágios já descritos por Piaget de forma que necessite de mais tempo para aprendizagem, tais recursos interativos seriam os mais recomendados.

Gráfico 2 - Nível de interação dos alunos com os materiais didáticos produzidos, segundo os critérios propostos neste estudo

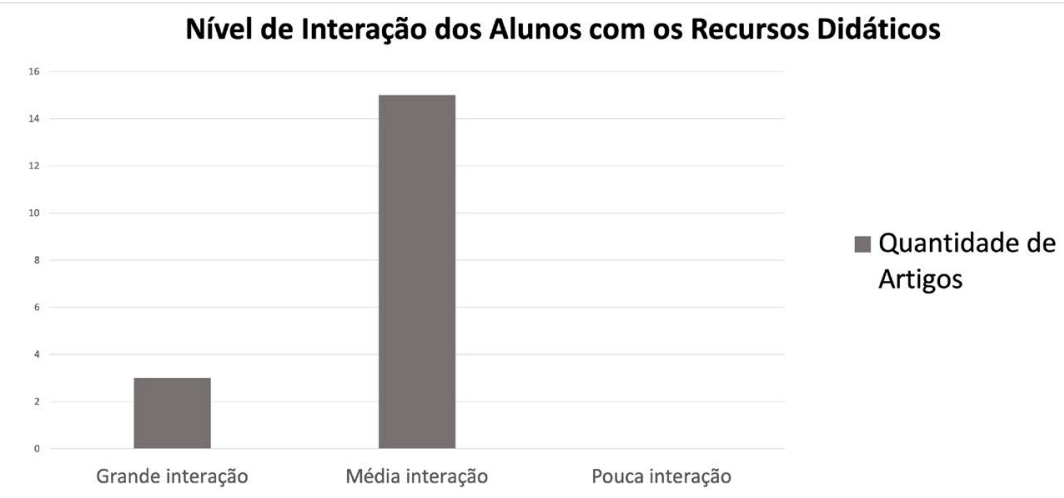

Fonte: elaborado pelas autoras.

Verificou-se que a maioria dos recursos didáticos avaliados eram de média interação e foram utilizados materiais de diferentes cores, texturas e tamanhos para construção dos modelos criados pelos autores das publicações encontradas, indicando ajuste à realidade compreensiva dos alunos, tanto os com deficiência, quanto os demais. Destaca-se a necessidade de haver descrições acompanhadas de explicações por parte do educador que alcancem as necessidades de cada deficiência como, por exemplo, incluir termos escritos em braille, figuras em Libras e/ou textos com letras grandes, assim como é realizado em determinados artigos. Outro ponto interessante é que, na maioria dos recursos didáticos propostos nas publicações, é utilizado material de baixo custo, dentre eles materiais recicláveis e de fácil manuseio e montagem, aumentando a possibilidade de educadores construírem recursos com base nos artigos e os utilizarem em sala de aula. 


\section{Considerações Finais}

O presente estudo teve como fundamento buscar uma maneira de colaborar com as escolas no alcance da meta presente no Plano Nacional da Educação e nas diversas leis e decretos vinculados à inclusão de pessoas com necessidades especiais na escola, porque são necessários avanços, no Brasil, para educar todas as crianças. Por sua vez, tais preocupações atingem áreas específicas do conhecimento como as Ciências Biológicas, sugerindo ajustes no ensino de Biologia para a inclusão. A elaboração de recursos didáticos e o desenvolvimento de metodologias de ensino que envolvem a interação do aluno com o recurso favorecem a inclusão do aluno no ensino regular e também no ensino de alunos que estão nas escolas exclusivas.

Para colaborar com ensino de Ciências Biológicas para alunos com necessidades especiais, analisou-se a diversidade de materiais didáticos proveniente de pesquisas publicadas em revistas da área de Educação / Ensino de Ciências. Foram levantados artigos de 2017 a 2016, sendo que de 2007 a 2010 não foram encontrados artigos nas revistas investigadas. Um total de 18 artigos foi encontrado. Os resultados desta análise indicaram que: (1) os recursos eram eram de média interação e, dificultando uma aula dinâmica e metodologias diferenciadas; (2) são apenas 18 artigos em 16 bases de dados e a maioria abordava aspectos abstratos da área de Ciências Biológicas, como as estruturas celulares; (3) os recursos eram, na maioria, preparados para alunos com necessidades visuais, demonstrando a carência de estudos relacionados às outras necessidades especiais; e, (4) há baixa diversidade de materiais sobre determinados conteúdos de Biologia. Materiais didáticos que necessitam apenas toque, como grande parte, pouco estimulam o aluno e pouco acrescentam aos recursos existentes como apoio ao ensino tradicional, que não valoriza o aluno ativo.

Como ponto favorável, os materiais didáticos encontrados apresentaram baixo custo, tornando-se acessível a educadores e demonstram média interação com o aluno, indicando avanço no tipo de interação que se tem com o recurso. Sugere-se a elaboração de materiais que trabalhem mais a capacidade manual e intelectual dos alunos, incentivando criatividade e habilidades em que os estudantes possam modificar, buscando atender a realidade de diferentes necessidades educativas.

Conclui-se que até o presente momento, poucos estudos abordam a criação de recursos didáticos para alunos com necessidades especiais no ensino de Ciências Biológicas e, dentre os existentes, a maioria dos trabalhos (12 em 18) se refere especificamente à célula e aos conteúdos microscópicos ou ultramicroscópicos (como as moléculas). Há a necessidade da criação de recursos didáticos que abordem áreas que estes trabalhos não abordam, de forma alinhada a metodologias contextualizadas e com situações problemas, incluindo Meio Ambiente, por exemplo.

Por fim, estima-se que o uso de recursos didáticos em propostas metodológicas elaboradas pelo professor é importante dentro da sala de aula, seja em escolas exclusivas ou em escolas regulares. Divulgar estas pesquisas e apropriar-se dos resultados nas escolas é tarefa de cunho coletivo, de pesquisadores, revistas acadêmicas e sistemas de ensino para maior sensibilização, participação dos alunos e aprendizagem em Biologia e nas diversas áreas do conhecimento. Com o levantamento realizado neste artigo, espera-se colaborar com a temática da inclusão em pesquisas na área do ensino de Ciências Biológicas e auxiliar o aluno com deficiência a aprender de maneira lúdica o mesmo conteúdo que outros alunos que estão em 
sua sala de aula, bem como a sua socialização, facilitando a compreensão do meio em que está inserido, de maneira a incluí-lo de forma efetiva na sala de aula.

\section{Referências}

ANDRADE, M. L. F; MASSABNI, V. G. O desenvolvimento de atividades práticas na escola: um desafio para os professores de ciências. Ciência \& Educação, Bauru, v. 17, n. 4, p. 835-854, 2011. DOI: https://doi.org/10.1590/S1516-73132011000400005.

BASSO, S. P. S. et al. Material didático multissensorial: a fecundação para deficientes visuais. Revista da SBEnBio, Niterói, n. 5, p. 1-16, 2012. Trabalho apresentado no IV ENEBIO e II EREBIO da Regional 4, Goiânia, 2012.

BENITE, C. R. M. et al. A experimentação no ensino de química para deficientes visuais com o uso de tecnologia assistiva: o termômetro vocalizado. Química Nova na Escola, São Paulo, v. 39, n. 3, p. 245-249, 2017. DOI: https://doi.org/10.21577/0104-8899.20160081.

BRASIL. [Constituição (1988)]. Constituição da República Federativa do Brasil. Brasilia: Imprensa Oficial, 2010.

BRASIL. Decreto $n^{\circ}$ 5.626/05, de 22 de dezembro de 2005. Regulamenta a lei $\mathrm{n}^{\circ} 10.436$, de 24 de abril de 2002, que dispõe sobre a Língua Brasileira de Sinais - Libras, e o art. 18 da Lei $\mathrm{n}^{\mathrm{o}}$ 10.098, de 19 de dezembro de 2000. Diário Oficial da União: seção 1, Brasília, 23 dez. 2005.

BRASIL. Lei no 9.394, de 20 de dezembro de 1996. Estabelece as diretrizes e bases da educação nacional. Diário Oficial da União, Brasília, 23 dez. 1996.

BRASIL. Lei n ${ }^{\circ}$ 10.436, de 24 de abril de 2002. Dispõe sobre a Língua Brasileira de Sinais Libras e dá outras providências. Diário Oficial da União, Brasília, 24 abr. 2002.

BRASIL. Lei $\mathbf{n}^{\circ} \mathbf{1 3 . 0 0 5}$, de 25 de junho de 2014. Aprova o plano nacional de educação PNE e dá outras providências. Brasília: Presidência da República, 2014a.

BRASIL. Ministério da Educação. Planejando a próxima década: conhecendo as 20 metas do plano nacional de educação. Brasília: MEC, 2014b. Disponível em: http://pne.mec.gov. br/images/pdf/pne_conhecendo_20_metas.pdf. Acesso em: 23 abr. 2019.

BRASIL. Ministério da Educação. O plano de desenvolvimento da educação: razões, princípios e programas. Brasília: MEC, [2007]. Disponível em: http://portal.mec.gov.br/ arquivos/livro/livro.pdf. Acesso em: 23 abr. 2019.

BRASIL. Ministério da Educação. Política nacional de educação especial na perspectiva da educação inclusiva. Brasília: MEC, 2008. Disponível em: http:/ / portal.mec.gov.br/ arquivos/pdf/politicaeducespecial.pdf. Acesso em: 23 abr. 2019.

BRASIL. Subsecretaria Nacional de Promoção dos Direitos da Pessoa com Deficiência.

Tecnologia assistiva. Brasília: CORDE, 2009. 
CACHAPUZ, A. et al. A necessária renovação do ensino das ciências. São Paulo: Cortez, 2005.

CECCANTI, G. Os tecidos vegetais têm três dimensões. Revista Brasileira de

Botânica, São Paulo, v. 29, n. 2, p. 335-337, 2006. DOI: https://doi.org/10.1590/S010084042006000200015.

FLORES, A. S. Recursos didáticos direcionados como complemento ao ensino de biologia para professores com deficiência visual: um estudo de caso. 2016. Trabalho de conclusão de curso (Bacharelado em ciências biológicas) - Faculdade de Engenharia de Ilha Solteira, Universidade Estadual Paulista, 2016. (Artigo 13)

INSTITUTO NACIONAL DE ESTUDOES E PESQUISAS EDUCACIONAIS ANÍSIO TEIXEIRA. Sinopse estatística da educação básica 2016. Brasília: Inep, 2017. Disponível em: http://inep.gov.br/web/guest/sinopses-estatisticas-da-educacao-basica. Acesso em: 23 abr. 2019.

KRASILCHIK, M. Caminhos do ensino de ciências no Brasil. Em Aberto, Brasília, ano 11, n. 55, p. 3-8, jul./set. 1992. Disponível em: http://emaberto.inep.gov.br/index.php/ emaberto/article/view/1851/1822. Acesso em: 24 abr. 2019.

LAGUNA, J. C. A utilização de diferentes recursos pedagógicos como auxílio na aprendizagem de alunos com deficiência visual. 2012. Trabalho de conclusão de curso (Especialização em Educação) - Universidade Tecnológica Federal do Paraná, Medianeira, 2012.

LOPES, N. R.; ALMEIDA, L. A.; AMADO, M. V. Produção e análise de recursos didáticos para ensinar alunos com deficiência visual o conteúdo de mitose: uma pratica pedagógica no ensino de ciências biológicas. Debates em Educação Científica e Tecnológica, Vitória, v. 2, n. 2, 2012.

MANTOAN, M. T. E. Todas as crianças são bem-vindas à escola. Profissão Docente, Uberaba, v. 1, n. 2, p. 1-19, 2001. Disponível em: http://www.revistas.uniube.br/index.php/ rpd/article/view/32/515. Acesso em: 25 abr. 2019.

NEPOMUCENO, T. A. R. Uma análise dos recursos didáticos táteis adaptados ao ensino de ciências a alunos com deficiência visual inseridos no ensino fundamental. Benjamin Constant, Rio de Janeiro, ano 21, n. 58, v. 1, p. 49-63, jan.-jun. 2015.

PAUlETTI, J.; BELUSSO, A.; BRITO, G. C.; REIS, J. G.; VOLTOLINI, C. H. Modelo didático tridimensional de epiderme foliar como estratégia para inclusão de alunos com deficiência visual no ensino de botânica. Revista da SBEnBio, Niterói, n. 7, 2014.

PAULINO, A. L. S; VAZ, J. M. C.; BAZON, F. V. M. Materiais adaptados para ensino de biologia como recursos de inclusão de alunos com deficiência visual. In: ENCONTRO DA ASSOCIAÇÃO BRASILEIRA DE PESQUISADORES EM EDUCAÇÃO ESPECIAL, 7., 2011, Londrina. Anais [...]. Disponível em: http://www.uel.br/eventos/ congressomultidisciplinar/pages/arquivos/anais/2011/processo_inclusivo/063-2011.pdf.

Acesso em: 25 abr. 2019. 
PIAGET, J. Abstração reflexionante: relações lógico-aritméticas e ordem das relações espaciais. Porto Alegre: Artes Médicas, 1995.

PIAGET, J.; INHELDER, B. A psicologia da criança. São Paulo: DIFEL, 1982.

POZO, J. I.; GÓMEZ CRESPO, M. A. G. A aprendizagem e o ensino de ciências: do conhecimento cotidiano ao conhecimento cientifico. Porto Alegre: Artmed, 2009.

SILVA, T. S.; LANDIM, M. F. Tendências de pesquisas em ensino de ciências voltadas a alunos com deficiência visual. Scientia Plena, Aracaju, v. 10, n. 4, p. 1-12, 2014.

TEIXEIRA, R. S.; SOUZA, R. O. L. Análise de materiais educativos utilizados como ferramenta para a educação ambiental de estudantes de escolas públicas do Rio de Janeiro. Revista Eletrônica em Gestão, Educação e Tecnologia Ambiental, Santa Maria, v. 19, n. 2, p. 1032-1037, 2015.

UNESCO. Programa en pro de la ciencia: marco general de acción. In: CONFERENCIA MUNDIAL SOBRE LA CIENCIA, 1999, Budapeste. Disponível em: http://www.unesco. org/science/wcs/esp/marco_accion_s.htm. Acesso em: 23 abr. 2019.

Artigo recebido em 07/08/2018. Aceito em 07/12/2018.

Contato: Rua Armando de O. Cobra, Jardim Aquarius, São José dos Campos, SP, 12246-002, Brasil. 